\title{
Hepatoprotective potential of zingerone against nonalcoholic fatty liver disease in rats fed with fructose-enriched diet
}

\author{
Jeyabarathy Muniandy Narayanan ${ }^{1,2}$ and Victor A. S. Jesudoss ${ }^{1}$ \\ ${ }^{1}$ Faculty of Pharmacy, Asia Metropolitan University, Batu 9, Cheras 43200, Selangor, Malaysia \\ ${ }^{2}$ Faculty of Pharmacy, Bendigo Campus, La Trobe University, Bendigo 3552, Australia
}

\begin{abstract}
Overconsumption of fructose increases the risk of nonalcoholic fatty liver disease (NAFLD), obesity and metabolic syndrome. NAFLD is currently one of the most common etiologies of chronic liver disease worldwide. The aim of the present study is to evaluate the hepatoprotective potential of zingerone against fructose-enriched diet-induced rat model of nonalcoholic fatty liver disease. Male albino Wistar rats were used and randomly divided into four groups: group 1, control rats fed with standard pellet; group 2, rats were fed normal pellet with intragastric intubation of zingerone $(100 \mathrm{mg} / \mathrm{kg} /$ day); group 3, rats were fed fructose enriched diet alone; group 4, rats were fed fructose enriched diet with intragastric intubation of zingerone $(100 \mathrm{mg} / \mathrm{kg} /$ day). Body weight, abdominal circumference, blood glucose, lipid profile and hepatic function indicators were increased and HDL reduced in group 3 rats. Liver pathology of group 3 showed marked changes which includes microand macrovesicular steatosis, marked inflammatory cell infiltration, sinusoidal fibrosis and with a significant increase in the area percentage of the collagen. Administration of zingerone reversed the fructose enriched diet induced changes especially body weight, abdominal circumference, blood glucose, lipid profile, hepatic function indicators and restored pathological alteration of liver. Taken together these data provide new insights into the preventive approach of zingerone against the development of the NAFLD.
\end{abstract}

Key words: Nonalcoholic fatty liver disease - Steatosis - Fructose-enriched diet - Zingerone

\section{Introduction}

Nonalcoholic fatty liver disease (NAFLD) portrays the entire spectrum of common liver disease that ranges from simple steatosis of the liver to progressive inflammation and fibrosis, resulting in nonalcoholic steatosis (NASH) and cirrhosis. NAFLD is among the cause of fatty liver and one of the leading etiologies of chronic liver disease (Chalasani et al. 2012). NAFLD is the hepatic manifestation of the metabolic syndrome, a cluster of closely related clinical features linked to visceral obesity, hyperlipidemia, insulin resistance, and type 2 diabetes (Alberti et al. 2005). NAFLD is seen worldwide and is considered the most common liver disorder in Western countries. The worldwide estimated prevalence

Correspondence to: Victor Antony Santiago Jesudoss, Faculty of Pharmacy, Asia Metropolitan University, Batu 9, Cheras 43200, Selangor, Malaysia

E-mail: jvictorbiochem@gmail.com of NAFLD ranges from $6.3 \%$ to $33 \%$ in the general population with a median prevalence of $20 \%$ (Vernon et al. 2011). The prevalence of fatty liver is even higher in persons with type 2 diabetes (50\%), obesity (76\%) and morbid obesity (nearly 100\%) (Adams et al. 2005). The prevalence in Asian population ranges from $6 \%$ up to $25 \%$ (Fan 2007). Community based studies from the Asia-Pacific region including India (Mohan et al. 2009), Malaysia (Magosso et al. 2010) and Singapore (Chow et al. 2007) demonstrated a continued rise in NAFLD prevalence with time.

The basis of the composition of fast food or cafeteria style food is high saturated fats, cholesterol and fructose (Tetri et al. 2008). Fructose in excess is known to promote de novo lipogenesis. In humans, higher amounts of fructose in the diet are associated with metabolic syndrome, obesity and NAFLD. Fructose promotes protein fructosylation and the formation of reactive oxygen species in the liver (Lim et al. 2010). The liver is exquisitely sensitive to changes in nutrient delivery and is uniquely suited to metabolize ingested fructose (Teff 
et al. 2004). A fructose-enriched diet induces higher degrees of macrovesicular and microvesicular steatosis and, in some experiments, inflammation and periportal fibrosis (Ackerman et al. 2005; Armutcu et al. 2005). The histological findings were accompanied by insulin resistance, dyslipidaemia, proinflammatory cytokines and hepatic lipid peroxidation. Experimental rats fed fructose-enriched diets are better model for NAFLD and NASH (Kawasaki et al. 2009).

In recent years, increasing attention has been paid to plant-based food components, with the hope of identifying its preventive effects. There has been considerable focus on the search for effective natural or pharmacological preventive agents. Ginger rhizome (Zingiber officinale) has received the attention of scientist due to its non-toxic, safe, potent activity and consumed worldwide as a spice and flavouring agent (Baliga et al. 2012). It has been widely used in indigenous medicines for the treatment of a variety of diseases and documented in the traditional system of Indian medicine (Ghayur and Gilani 2005). Zingerone (4-(4-hydroxy-3methoxyphenyl) butan-2-one) is a pharmacologically active component of dry ginger. It is used as a flavour in spice oils to introduce spicy aroma. Fresh ginger rhizome contains high amount of gingerol and low amount of zingerone. Cooking or drying transforms gingerol into zingerone through a retro-aldol reaction (Vriens et al. 2008).

Zingerone has been shown to have wide range of pharmacological properties including ability to scavenge free radicals (Aeschbach et al. 1994), high antioxidant activity as compared to ascorbic acid (Rajan et al. 2013), suppress lipid peroxidation (Rajakumar and Rao 1994), antioxidant (Kabuto et al. 2005), anti-inflammatory (Chung et al. 2009), anticancer (Rao et al. 2009; Al-Daghri et al. 2012), antimicrobial activity (Singh et al. 2008; Manjunatha et al. 2013; Kumar et al. 2013) and protective effect against $E$. coli-induced diarrhoea (Chen et al. 2007).

This study provides the scientific evidence for the hepatoprotective potential of zingerone against fructose-enriched diet-induced nonalcoholic fatty liver disease by evaluating histopathology of liver, hepatic function indicators and lipid profile in control and experimental rats.

\section{Materials and Methods}

\section{Chemicals}

Zingerone (Order No: SSC/QUO/10-11/850) was purchased from Sigma Chemical Co., St. Louis, MO, USA. All the assay kits were procured from Qualichem (Sea) Sdn. Bhd., Selangor Darul Ehsan, Malaysia and Human Gesellschaft fur Biochemica und Diagnostica mbH, Weisbaden, Germany. All other chemicals and reagents used were of analytical grade.

\section{Animal care and diet}

All experimental protocols were approved by the Institutional Animal Ethical Committee of Asia Metropolitan University (AMU), Cheras, Selangor, Malaysia. Twentyfour healthy 6 weeks old male albino Wistar rats weighing 150-240 g were obtained from Animal House Unit, AMU. The rats were housed in propylene cages with husk for bedding within a barrier facility at the Central Animal House, AMU. Rats were placed under controlled room temperature $\left(25 \pm 2^{\circ} \mathrm{C}\right)$ with relative humidity $(45 \pm 5 \%)$, on $12 \mathrm{~h}$ light/ dark cycle. Upon arrival, the rats were allowed 1 week for acclimatization and provided with free access to standard pellet diet and water before the commencement of dietary intervention.

At the start of the experiment, control groups were fed standard pellet diet with corn starch and water ad libitum and other experimental NAFLD groups were fed with fructoseenriched diet which comprises $40 \%$ fructose in diet and $20 \%$ fructose in drinking water. All measures were taken to ensure uniform mixing of the additives of the diet before kneading using a little water.

\section{Experimental design}

After the acclimatization phase, rats were assorted into four experimental groups (6 in each) using a randomization process designed to ensure comparable initial body weights in all study protocols. Rats were divided into four groups. Group 1 (CON): rats were fed standard pellet diet with corn starch and $0.5 \%(\mathrm{w} / \mathrm{v})$ carboxy methyl cellulose (CMC) in water throughout the experimental period and treated as vehicle control. Group 2 (ZIN): rats were fed normal pellet diet and zingerone at the dose of $100 \mathrm{mg} / \mathrm{kg}$ body weight via intragastric intubation every day throughout the experimental period. Group 3 (FED): rats were fed fructose-enriched diet throughout the experimental period. Group 4 (FED+ZIN): rats were fed fructose enriched diet and zingerone at the dose of $100 \mathrm{mg} / \mathrm{kg}$ body weight via intragastric intubation every day throughout the experimental period.

\section{Preparation of zingerone suspension}

Zingerone was suspended in $0.5 \%$ carboxy methyl cellulose just before treatment and each rats in experimental groups received $100 \mathrm{mg} / \mathrm{kg}$ body weight of zingerone by intragastric intubation every day throughout the experimental period of 8 weeks.

\section{Physiological and metabolic variables}

Rats were clinically examined every week and body weights of the rats were measured weekly to allow accurate dosing 
with zingerone. Metabolic measurements (food intake and water intake) were recorded for all the rats to determine fructose dosage. Abdominal circumference and body length of rats were measured using a standard measuring tape on the first day and last day of the experiment.

\section{Terminal experiments}

On the day before euthanasia, the rats were deprived of food overnight and anaesthetized, and then, rats were euthanized. Blood was collected in tubes containing clotting activator gel, after 10 min rest in the supine position, and centrifuged at $160 \times g$ for $10 \mathrm{~min}$. The serum was separated and used for the biochemical assays. Liver was carefully cleaned of adherent fat, connective tissue, weighed accurately and used for the histological and biochemical analysis.

\section{Biochemical assays}

The activities of serum aspartate transaminase (AST, EC 2.6.1.1), alanine transaminase (ALT, EC 2.6.1.2), and alkaline phosphatase (ALP, EC 3.1.3.1) were assayed spectrophotometrically according to the standard procedures using commercially available diagnostic kits (Qualichem (Sea) Sdn. Bhd., Selangor Darul Ehsan, Malaysia).

Lipids were extracted from hepatic tissues by the method of Folch et al. (1957). Serum HDL (high-density lipoprotein), total cholesterol and triglycerides, hepatic cholesterol and hepatic triglycerides were quantified spectrophotometrically according to the standard enzymatic procedures using commercially available diagnostic kits (Human Gesellschaft fur Biochemica und Diagnostica mbH, Weisbaden, Germany).

\section{Histological analysis}

Hepatic tissue was quickly removed after euthanasia, fixed in $10 \%$ buffered formalin for $48 \mathrm{~h}$, and processed by automated tissue processing machine (MTM II Tissue Processor, SLEE medical GmbH, Lise-Meitner-Str. 11, D-55129 Mainz, Germany), embedded in paraffin, and sectioned (5-6 $\mu \mathrm{m}$ thickness) using a microtome. Sections were stained with hematoxylin and eosin ( $\mathrm{H}$ and $\mathrm{E}$ ) dye and Masson trichrome stain and then mounted in a neutral deparaffinated xylene (DPX) medium using standard protocols. They were assessed using light microscopy and photographed.

\section{Image analysis and biomarker index of fibrosis}

A quantitative measurement of the percentage of hepatic fibrosis (collagen deposition) was determined using a computer assisted automated image analyzer (ImageJ/Fiji 1.46, Wyne Rasband, National Institutes of Health, Bethesda,
USA) by analyzing 10 random fields per slide. Biomarker index of fibrosis calculating the ratio of stained area (Masson's trichrome) corresponding to the fibrotic components (collagen) deposited in the extracellular matrix of the hepatic tissue to the whole area of the hepatic tissue. The evaluation of biomarker index of fibrosis was repeated on four different sections per rat's hepatic tissue and the average was calculated. A bar graph was plotted representing the mean \pm S.E.M of biomarker index of fibrosis in each experimental group.

\section{Data analysis}

The data are expressed as mean \pm SE. Comparisons of the determined variables among all the grouped data for biochemical and physiological parameters were analyzed statistically using one way analysis of variance (ANOVA) followed by Duncan's multiple range test using the SPSS software package, version 15.01 for windows and statistical significance was defined as $p<0.05$.

\section{Results}

\section{Physiological and metabolic variables}

Table 1 shows the weekly mean body weight of control and experimental groups. The body weight of rats in CON, ZIN, FED and FED+ZIN group were recorded and compared at the end of the study. The body weight of FED rat was significantly $(p<0.05)$ increased as compared to CON rats. Administration with zingerone ( $100 \mathrm{mg} / \mathrm{kg} \mathrm{b.w.)} \mathrm{significantly}$ $(p<0.05)$ decreased the body weight of FED+ZIN group as compared to FED group.

Statistically significant $(p<0.05)$ increase of the waist circumference and hepatic index (liver weight and body weight ratio) was observed in FED group as compared to CON group. Administration of zingerone (100 mg/kg b.w.) significantly reduced the waist circumference with decreased hepatic index of FED+ZIN group as compared to FED group (Table 1). There were no significant differences between the body length, food intake and water intake of FED and CON group during the experimental period.

\section{Hepatic markers}

Hepatic function indicator enzymes such as AST, ALT and ALP activities in the serum were elevated in FED group as compared to CON group. Administration of zingerone $(100 \mathrm{mg} / \mathrm{kg}$ b.w.) significantly $(p<0.05)$ reduced the activities of the hepatic function indicator enzymes in the serum in FED+ZIN group as compared to FED group (Table 2). 
Table 1. General characteristics of control and experimental rats

\begin{tabular}{|c|c|c|c|c|}
\hline \multirow{2}{*}{ Parameter } & \multicolumn{4}{|c|}{ Group } \\
\hline & $\mathrm{CON}$ & ZIN & FED & FED+ZIN \\
\hline Initial body weight (gm) & $185.00 \pm 6.41$ & $190.21 \pm 8.26$ & $186.00 \pm 7.49$ & $188.00 \pm 6.67$ \\
\hline Final body weight (gm) & $320.00 \pm 9.03^{\mathrm{a}}$ & $310.00 \pm 8.62^{\mathrm{a}}$ & $392.00 \pm 13.14^{\mathrm{b}}$ & $355.00 \pm 10.67^{\mathrm{c}}$ \\
\hline Liver weight $(\mathrm{gm})$ & $5.45 \pm 0.22^{\mathrm{a}}$ & $5.83 \pm 0.16^{\mathrm{a}}$ & $8.71 \pm 0.34^{\mathrm{b}}$ & $7.43 \pm 0.32^{\mathrm{c}}$ \\
\hline Hepatic index & $1.70 \pm 0.07^{\mathrm{a}}$ & $1.88 \pm 0.08^{\mathrm{a}}$ & $2.22 \pm 0.08^{\mathrm{b}}$ & $2.09 \pm 0.10^{b, c, *}$ \\
\hline Food intake & $15.32 \pm 0.63$ & $15.50 \pm 0.62$ & $16.32 \pm 0.62$ & $15.20 \pm 0.62$ \\
\hline Water intake & $33.21 \pm 1.32$ & $32.21 \pm 1.32$ & $34.31 \pm 1.31$ & $33.25 \pm 1.33$ \\
\hline Body length $(\mathrm{cm})$ & $24.00 \pm 0.94$ & $24.00 \pm 0.90$ & $24.00 \pm 1.07$ & $25.00 \pm 0.99$ \\
\hline BMI & $0.56 \pm 0.14$ & $0.54 \pm 0.14$ & $0.68 \pm 0.17^{*}$ & $0.57 \pm 0.12$ \\
\hline Waist circumference $(\mathrm{cm})$ & $20.10 \pm 0.86^{\mathrm{a}}$ & $20.50 \pm 0.86^{\mathrm{a}}$ & $25.50 \pm 1.03^{\mathrm{b}}$ & $23.00 \pm 0.90^{b, c, *}$ \\
\hline
\end{tabular}

All the values are expressed as mean \pm S.E. of 6 rats in each group. Groups not sharing a common superscript letter (a, b and c) differ significantly at $p<0.05$ (DMRT). Groups not sharing a common superscript symbol ${ }^{*}$ ) differ significantly at $p<0.001$ (DMRT).

\section{Lipid profile}

Statistically significant $(p<0.05)$ increased in the levels of serum lipids (total cholesterol and triglycerides) with decreased levels of HDL were observed in FED group as

Table 2. Effect of zingerone on activities of serum hepatic function indicators of control and experimental rats

\begin{tabular}{lrrr}
\hline Group & \multicolumn{1}{c}{ AST } & \multicolumn{1}{c}{ ALT } & \multicolumn{1}{c}{ ALP } \\
\hline CON & $72.16 \pm 1.72^{\mathrm{a}}$ & $68.73 \pm 2.42^{\mathrm{a}}$ & $31.02 \pm 1.19^{\mathrm{a}}$ \\
ZIN & $70.71 \pm 2.12^{\mathrm{a}}$ & $67.92 \pm 2.06^{\mathrm{a}}$ & $28.91 \pm 0.90^{\mathrm{a}}$ \\
FED & $180.82 \pm 6.90^{\mathrm{b}}$ & $196.62 \pm 6.95^{\mathrm{b}}$ & $48.92 \pm 1.60^{\mathrm{b}}$ \\
FED+ZIN & $79.92 \pm 2.84^{\mathrm{a}}$ & $121.29 \pm 4.19^{\mathrm{c}}$ & $30.64 \pm 0.86^{\mathrm{a}}$ \\
\hline
\end{tabular}

All the values are expressed as mean \pm S.E. of 6 rats in each group. Groups not sharing a common superscript letter ( $a, b$ and $c$ ) differ significantly at $p<0.05$ (DMRT). AST, aspartate transaminase; ALT, alanine transaminase; ALP, alkaline phosphatase. compared to CON group. Administration of zingerone (100 mg/kg b.w.) significantly reduced the levels of serum cholesterol and triglycerides and increased the serum HDL levels in FED+ZIN group as compared to FED group (Table 3).

Elevated levels of cholesterol and triglycerides in the hepatic tissue were observed in FED group as compared to CON group. Administration of zingerone $(100 \mathrm{mg} / \mathrm{kg}$ b.w.) reduced the cholesterol and triglycerides in hepatic tissue in FED+ZIN group as compared to FED group (Table 3).

\section{Blood glucose}

Statistically significant $(p<0.05)$ increased in the levels of blood glucose were observed in FED group as compared to CON group. Administration of zingerone $(100 \mathrm{mg} / \mathrm{kg}$ b.w.) significantly reduced the levels of blood glucose in FED+ZIN group as compared to FED group (Table 3).

Table 3. Effect of zingerone on levels of serum and hepatic lipids and glucose of control and experimental rats

\begin{tabular}{|c|c|c|c|c|}
\hline & \multicolumn{4}{|c|}{ Group } \\
\hline & $\mathrm{CON}$ & ZIN & FED & FED + ZIN \\
\hline \multicolumn{5}{|l|}{ Serum lipids } \\
\hline Triglycerides (mg/dl) & $65.81 \pm 2.84^{\mathrm{a}}$ & $64.91 \pm 2.43^{\mathrm{a}}$ & $165.92 \pm 6.53^{b}$ & $73.91 \pm 0.29^{\mathrm{a}}$ \\
\hline Total cholesterol (mg/dl) & $92.91 \pm 3.64^{\mathrm{a}}$ & $88.71 \pm 3.21^{\mathrm{a}}$ & $190.53 \pm 5.30^{b}$ & $131.45 \pm 5.67^{\mathrm{C}}$ \\
\hline HDL cholesterol (mg/dl) & $48.92 \pm 1.60^{\mathrm{a}}$ & $48.82 \pm 1.98^{\mathrm{a}}$ & $31.92 \pm 1.60^{\mathrm{b}}$ & $47.82 \pm 1.91^{\mathrm{a}}$ \\
\hline \multicolumn{5}{|l|}{ Hepatic lipids } \\
\hline Triglycerides (mg/mg tissue) & $3.35 \pm 0.13^{\mathrm{a}}$ & $3.11 \pm 0.11^{\mathrm{a}}$ & $5.90 \pm 0.18^{b}$ & $3.86 \pm 0.12^{\mathrm{c}}$ \\
\hline Cholesterol (mg/mg tissue) & $3.40 \pm 0.09^{\mathrm{a}}$ & $3.30 \pm 0.09^{\mathrm{a}}$ & $5.86 \pm 0.18^{\mathrm{b}}$ & $3.96 \pm 0.12^{\mathrm{c}}$ \\
\hline Blood glucose $(\mathrm{mg} / \mathrm{dl})$ & $112.10 \pm 4.60^{\mathrm{a}}$ & $104.80 \pm 4.19^{\mathrm{a}}$ & $210.00 \pm 8.29^{b}$ & $140.82 \pm 5.71^{\mathrm{a}}$ \\
\hline
\end{tabular}

All the values are expressed as mean \pm S.E. of 6 rats in each group. Groups not sharing a common superscript letter (a, b and c) differ significantly at $p<0.05$ (DMRT). HDL, high density lipoprotein. 
Histology of liver

Figure 1 represents photomicrographs of the hepatic tissue of control and experimental rats stained with hematoxylin and eosin at $40 \times$ standard light magnification. Control rats and zingerone-administrated rats showed normal hepatocytes with no pathological changes. Rats fed with fructoseenriched diet (FED group) caused marked changes in the hepatic tissue characterized by micro- and macrovesicular steatosis, marked inflammatory cell infiltration and sinusoidal fibrosis. Administration of zingerone (100 mg/kg b.w.) revealed reduced micro vesicular steatosis, marked inflammatory cell infiltration and sinusoidal fibrosis in FED+ZIN group as compared to FED group.

Figure 2A illustrates photomicrographs of Masson's trichrome staining of the hepatic tissue of control and experimental rats at $10 \times$ standard light magnification. Rats in FED group exhibited increased perisinusoidal, pericellular and interstitial collagen accumulation. Administration of zingerone $(100 \mathrm{mg} /$ $\mathrm{kg} \mathrm{b.w.)} \mathrm{revealed} \mathrm{mild} \mathrm{fibrous} \mathrm{septae} \mathrm{and} \mathrm{reduced} \mathrm{collagen} \mathrm{ac-}$ cumulation in FED+ZIN group as compared to FED group.

\section{Biomarker index of fibrosis}

Figure $2 \mathrm{~B}$ shows changes in the percentages of hepatic fibrosis (collagen deposition) in the experimental and control rats. Statistically significant $(p<0.05)$ increased in the percentages of hepatic fibrosis (collagen deposition) were observed in the photomicrographs of the hepatic tissue in FED group as compared to CON group. Administration of zingerone significantly reduced the levels of percentages of hepatic fibrosis (collagen deposition) in the photomicrographs of the hepatic tissue of rats from FED+ZIN group as compared to FED group.

\section{Discussion}

Diet rich in fruits and vegetables are in fact affordable, available and among the recommended lifestyle modifications to decrease the risk of degenerative disease and reduce the complications associated with metabolic disorders (Cecchini et al. 2010; Eslamparast et al. 2015). Hence we aimed to uncover the hepatoprotective potential of zingerone, a dietary constituent, using a well-established rodent model. Our present findings show that zingerone markedly prevents, attenuates and reverses hepatic steatosis and its progression to steatohepatitis of fructose-enriched diet-induced rat model of nonalcoholic fatty liver disease. Moreover, we have shown that daily administration of zingerone markedly modulates hepatic function indicators, lipid deposition and histology of liver tissue in a long-term preclinical model of NAFLD induced by fructose-enriched diet.

Diet rich in fructose lead to the development of NAFLD in rodents but may also result in the development of insulin resistance, dyslipidemia and oxidative stress (Spruss et al. 2012). Fructose is a potent steatogenic stimulus in the liver, largely due to the metabolism of fructose into glyceraldehyde-3-phosphate and dihydroxyacetone phosphate both of which are triglyceride synthetic precursors (Lim et al. 2010). Nutrients can be transformed in glucose and glycogen, but this pathway is very inefficient hence the liver choice is to
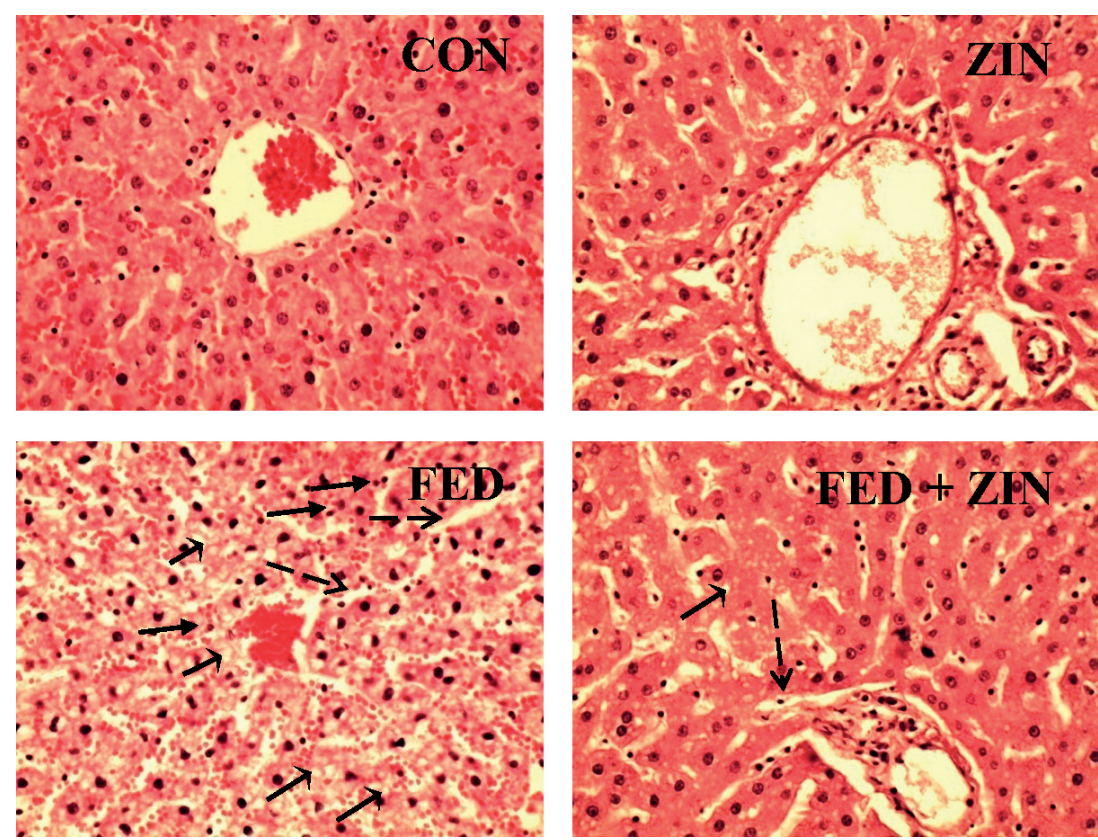

Figure 1. Photomicrographs of hematoxylin and eosin stained sections of rat liver from different experimental groups. CON: control group, shows normal hepatocytes with central portal vein. ZIN: zingerone administered group, shows normal hepatocytes with central portal vein with no pathological alterations. FED: fructose-enriched diet fed group, shows microvesicular steatosis $(\boldsymbol{\lambda})$, sinusoidal fibrosis $(\boldsymbol{\nearrow})$ and marked inflammatory cell infiltration $(\boldsymbol{\nabla})$. FED+ZIN: fructose-enriched diet and zingerone-administered group, shows reduced microvesicular steatosis, sinusoidal fibrosis and marked inflammatory cell infiltration. 
A
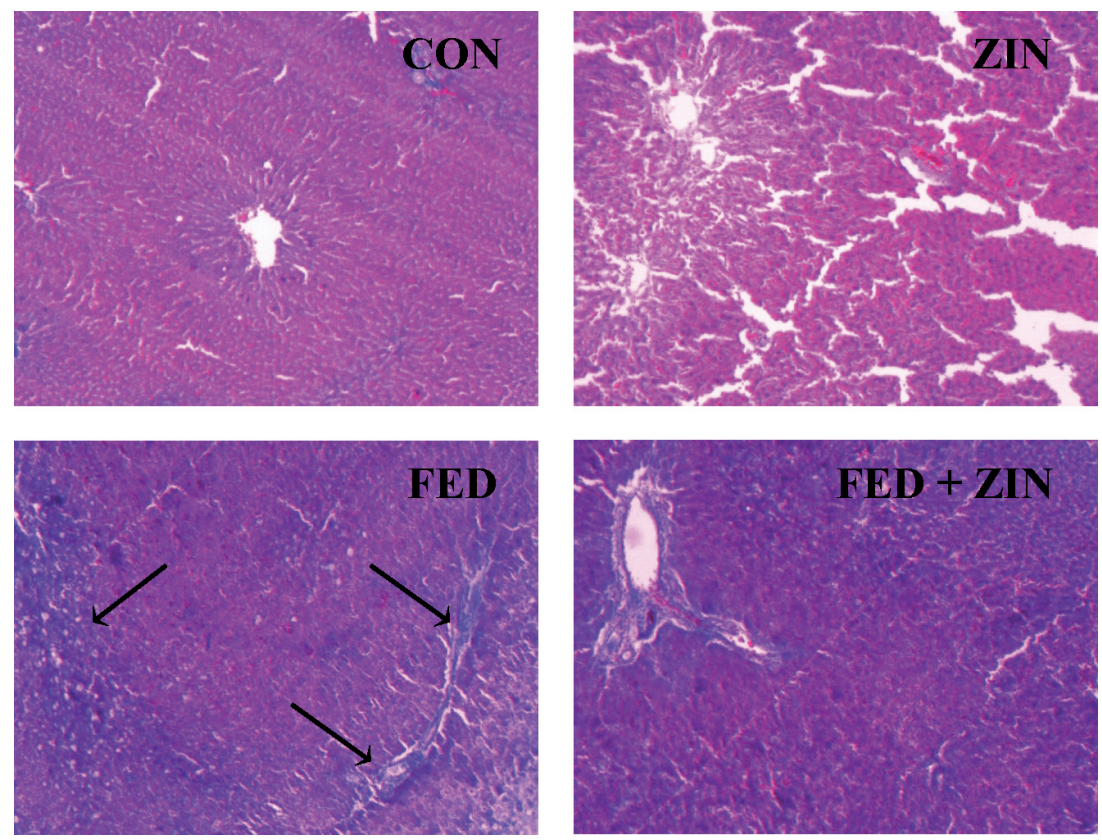

B

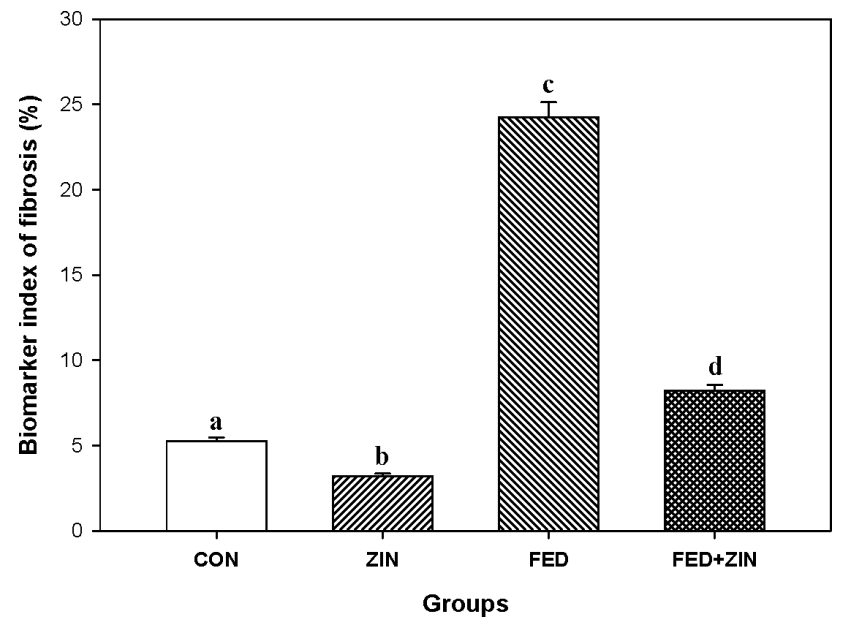

produce pyruvate, which is transferred to mitochondria and is transformed in fatty acids. These fatty acids are used mainly as liver energy source, stored as triglycerides depots or released in the blood stream as very low-density lipoprotein and fatty acids. This characteristic makes fructose a highly lipogenic nutrient (Basciano et al. 2005). Increased retention of lipids in the hepatocytes, mostly in the form of cholesterol, triglycerides and fatty acids are known to be the common early trait of NAFLD (Te Sligte et al. 2004). According to this hypothesis, for the mechanism of disease progression, an initial insult occurs during the development of macrovesicular steatosis due to excessive triglyceride accumulation in the
Figure 2. Photomicrographs of Masson trichrome stained sections of rat liver (A) and changes in the percentages of hepatic fibrosis (collagen deposition) (B) in the experimental and control rats. Perisinusoidal, pericellular deposition of collagen and interstitial collagen accumulation $(\boldsymbol{\nearrow})$. Data are expressed as the mean \pm S.E.M. Groups not sharing a common superscript letter (a, b, c and d) differ significantly at $p<0.05$ (DMRT). CON, control group; $\mathrm{ZIN}$, zingerone-administered group; FED, fructose-enriched diet fed group; FED+ZIN, fructose-enriched diet and zingeroneadministered group.

liver. Increase in visceral adipose tissue and intra hepatic fat correlates with increased gluconeogenesis, increased fatty acid levels, and insulin resistance (Gastaldelli et al. 2007). Insulin resistance and subsequent hyperinsulinemia appear to be the major factors behind the alterations in the hepatic pathways of uptake, synthesis, degradation, and secretion of fatty acid which ultimately leads to accumulation of lipids in the hepatocytes. This impact makes the liver susceptible to a second insult, resulting in an inflammatory response and progression of liver damage. The second hit occurs due to increased hepatic oxidative stress which is associated with increased fatty acid metabolism, diminished antioxidant ac- 
tivity, increased pro-inflammatory cytokines, such as tumour necrosis factor alpha and endotoxin levels, and especially mitochondrial dysfunction and/or endoplasmic reticulum stress in the liver (Sanyal et al. 2001). Higher levels of oxidative stress in the liver are found in animal models of NAFLD (Lieber et al. 2004). Oxidative stress is a result of increased hepatic fat load, decreased content of antioxidants, reduced activities of enzymes involved in the metabolism of reactive oxygen species, raised pro-inflammatory cytokines, activation of Kupffer cells, and mitochondrial dysfunction (Malaguarnera et al. 2009). In consistent with previous findings by Basciano et al. (2005) and Kawasaki et al. (2009); in our present study, fructose-enriched diet fed rats showed increased glucose, triglycerides and cholesterol in serum and hepatic tissue whereas serum HDL levels were decreased.

Zingerone increased norepinephrine induced lipolysis associated with the translocation of hormone sensitive lipase from the cytosol to lipid droplets in adipocytes which indicate that zingerone may prevent the fat storage through increasing norepinephrine-induced lipolysis in adipocytes (Han et al. 2008). Peroxisome proliferator activated receptors (PPARs), members of the nuclear hormone receptor family, are key regulators of various metabolic pathways related to lipid and glucose metabolism as well as inflammation. Zingerone exerts its potent anti-inflammatory action by increasing hepatic nuclear factor- 4 and PPAR activities, while suppressing nuclear factor- $\kappa \mathrm{B}$ activity (Chung et al. 2009). Pretreatment with zingerone prevented hyperlipidemia especially serum and heart cholesterol and triglycerides, improves serum HDL and activity of liver 3-hydroxy3-methyl glutaryl-coenzyme-A-reductase in isoproterenolinduced myocardial infarcted rats (Hemalatha and Stanely Mainzen Prince 2015). Consistent with the previous finding by Chung et al. (2009), Han et al. (2008), Hemalatha and Stanely Mainzen Prince (2015); in our study, zingerone administration to fructose-enriched diet rats ameliorates the levels of serum cholesterol, triglycerides, glucose, HDL and hepatic lipids. Thus zingerone by ameliorating serum lipids and hepatic lipids effectively protects hepatic tissues against fructose-enriched diet induced NAFLD and NASH in rats and henceforth it could be considered as a good candidate for hepatic steatosis.

AST, ALT and ALP are the relatively liver-specific enzymes. Elevation of AST, ALT and ALP activities in the serum is the result of leakage from damaged cells and therefore reflects hepatocyte damage (Loria et al. 2005). Mild to moderate elevation in the serum activities of AST and ALT or both is the most common and often the only laboratory abnormality found in patients with NAFLD. The elevated AST or ALT to NAFLD hypothesis seems to be valid provided that common alternative chronic liver diseases are excluded and affected patients have one of more features of the metabolic syndrome (Yu and Keeffe 2003).
The imbalance between the production and the removal of free radicals is intimately linked to a structural damage and cellular injury; this was confirmed by the increase in the AST/ALT ratio (markers of liver damage) in the fructoseenriched diet fed rats. Alterations in the levels of serum AST and ALT are considered important markers of hepatic injury and liver fibrosis (Rafiq and Younossi 2009). Stored hepatic triglycerides are related to acute local insulin resistance. This mechanism can be resulted of a local pro-inflammatory response which alters the circulating AST/ALT ratio (Botezelli et al. 2010). In our present study, fructose-enriched diet fed rats showed elevated serum hepatic function indicator enzymes (ALT, AST and ALP) activities which are strongly correlated to NAFLD and NASH.

Zingerone is a potent antioxidant (Hemalatha and Prince 2015), reduces oxidative stress and lipid peroxidation (Vinothkumar et al. 2014; Hemalatha and Prince 2015) and also protects against reactive oxygen species mediated DNA damage (Rajan et al. 2013). Zingerone is a potent antiinflammatory phytomedicine by down regulating hepatic tissue damage markers (AST, ALT, ALP) and inflammatory cytokines (MIP-2, IL-6 and TNF- $\alpha$ ) of hepatic inflammation induced by antibiotic-mediated endotoxemia (Kumar et al. 2014). Consistent with the previous finding by Kumar et al. (2014) in our study, zingerone administration to fructose-enriched diet rats attenuated the activities of the serum hepatic function indicators enzymes. These evidences demonstrate that long-term administration of zingerone prevented the fructose- enriched diet induced hepatic damage.

Liver biopsy or histology currently represents the diagnostic gold standard for NAFLD (Adams and Feldstein 2010). Diagnosis for NAFLD and NASH are confirmed when a liver pathology shows the presence of perilobular inflammation or the presence of hepatocyte ballooning, mallory hyaline and acidophil bodies with or without fibrosis (Lewis and Mohanty 2010). In consistent with previous findings by Ackerman et al. (2005), Armutcu et al. (2005) and Kawasaki et al. (2009); in our present study, liver histology of fructoseenriched diet fed rats showed micro- and macrovesicular steatosis, polymorphonuclear infiltrates, centrilobular inflammation, sinusoidal fibrosis, perisinusoidal, and pericellular deposition of collagen (fibrosis). These evidences demonstrate a systemic pathological change on long-term administration of fructose-enriched diet, which are features of NAFLD and NASH. Intragastric intubation of zingerone to fructose-enriched diet showed mild signs of microvesicular steatosis and centrilobular inflammation in the hepatic tissue and visualized through haemotoxylin and eosin stain. Staining of Masson's trichrome showed mild signs of perisinusoidal and pericellular deposition of collagen (fibrosis) in fructose-enriched diet fed rats with zingerone.

In conclusion, our results strongly suggest that fructoseenriched diet induce drastic changes in the biochemical and 
histological and also aggravate the nonalcoholic fatty liver disease. Furthermore, fructose-enriched diet strengthen "first hit" and promote "second hit" hypothesis leading to NAFLD and/or NASH. Administration of zingerone ameliorates the biochemical changes in the liver especially the hepatic lipids accumulation, liver function indicators and hepatic histology. Since nonalcoholic hepatic steatosis (NASH) is highly sensitive to dietary intervention, patients with liver fibrosis could markedly benefit from zingerone. Zingerone is a nontoxic, inexpensive dietary natural compound with action of potential pharmacological activities with no side effect. The present study is experimental evidence indicating that dietary zingerone could be considered as a useful strategy for the intervention of NAFLD.

\section{References}

Ackerman Z., Oron-Herman M., Grozovski M., Rosenthal T., Pappo O., Link G., Sela B. A. (2005): Fructose-induced fatty liver disease: hepatic effects of blood pressure and plasma triglyceride reduction. Hypertension 45, 1012-1018 http://dx.doi.org/10.1161/01.HYP.0000164570.20420.67

Adams L. A, Feldstein A. E. (2010): Nonalcoholic steatohepatitis: risk factors and diagnosis. Expert Rev. Gastroenterol. Hepatol. 4, 623-635 http://dx.doi.org/10.1586/egh.10.56

Adams L. A., Lymp J. F. St Sauver J., Sanderson S. O., Lindor K. D., Feldstein A., Angulo P. (2005): The natural history of nonalcoholic fatty liver disease: a population-based cohort study. Gastroenterology 129, 113-121 http://dx.doi.org/10.1053/j.gastro.2005.04.014

Aeschbach R., Löliger J., Scott B. C., Murcia A., Butler J., Halliwell B., Aruoma O. I. (1994): Antioxidant actions of thymol, carvacrol, 6-gingerol, zingerone and hydroxytyrosol. Food. Chem. Toxicol. 32, 31-36 http://dx.doi.org/10.1016/0278-6915(84)90033-4

Alberti K. G., Zimmet P., Shaw J., IDF Epidemiology Task Force Consensus Group (2005): The metabolic syndrome--a new worldwide definition. Lancet 366, 1059-1062 http://dx.doi.org/10.1016/S0140-6736(05)67402-8

Al-Daghri N. M., Alokail M. S., Alkharfy K. M., Mohammed A. K., Abd-Alrahman S. H., Yakout S. M., Amer O. E. Krishnaswamy S. (2012): Fenugreek extract as an inducer of cellular death via autophagy in human T lymphoma Jurkat cells. BMC Complement. Altern. Med. 30, 202 http://dx.doi.org/10.1186/1472-6882-12-202

Armutcu F., Coskun O., Gürel A., Kanter M., Can M., Ucar F., Unalacak M. (2005): Thymosin alpha 1 attenuates lipid peroxidation and improves fructose-induced steatohepatitis in rats. Clin. Biochem. 38, 540-547 http://dx.doi.org/10.1016/j.clinbiochem.2005.01.013

Baliga M. S., Haniadka R., Pereira M. M., Thilakchand K. R., Rao S., Arora R. (2012): Radioprotective effects of Zingiber officinale Roscoe (ginger): past, present and future. Food Funct. 3, 714-723 http://dx.doi.org/10.1039/c2fo10225k
Basciano H., Federico L., Adeli K. (2005): Fructose, insulin resistance, and metabolic dyslipidemia. Nutr. Metab. (Lond.) 2, 5 http://dx.doi.org/10.1186/1743-7075-2-5

Botezelli J. D., Mora R. F., Dalia R. A., Moura L. P., Cambri L. T. Ghezzi A. C. Voltarelli, F. A. Mello M. A. (2010): Exercise counteracts fatty liver disease in rats fed on fructose-rich diet. Lipids Health Dis. 9, 116

http://dx.doi.org/10.1186/1476-511X-9-116

Cecchini M., Sassi F., Lauer J. A., Lee Y. Y., Guajardo-Barron V., Chisholm D. (2010): Tackling of unhealthy diets, physical inactivity, and obesity: health effects and cost-effectiveness. Lancet 376, 1775-1784 http://dx.doi.org/10.1016/S0140-6736(10)61514-0

Chalasani N., Younossi Z., Lavine J. E., Diehl A. M., Brunt E. M., Cusi K., Charlton M., Sanyal A. J.; American Gastroenterological Association; American Association for the Study of Liver Diseases; American College of Gastroenterologyh (2012): The diagnosis and management of non-alcoholic fatty liver disease: practice guideline by the American Gastroenterological Association, American Association for the Study of Liver Diseases, and American College of Gastroenterology. Gastroenterology 142, 1592-1609 http://dx.doi.org/10.1053/j.gastro.2012.04.001

Chen J. C., Huang L. J., Wu S. L., Kuo S. C., Ho T. Y., Hsiang C. Y. (2007): Ginger and its bioactive component inhibit enterotoxigenic Escherichia coli heat-labile enterotoxin-induced diarrhea in mice. J. Agric. Food Chem. 55, 8390-8397 http://dx.doi.org/10.1021/jf071460f

Chow W. C., Tai E. S., Lian S. C., Tan C. K., Sng I., Ng H. S. (2007): Significant non-alcoholic fatty liver disease is found in nondiabetic, pre-obese Chinese in Singapore. Singapore Med. J. 48, 752-757

Chung S. W., Kim M. K., Chung J. H., Kim D. H., Choi J. S., Anton S., Seo A. Y., Park K. Y., Yokozawa T., Rhee S. H., Yu B. P., Chung H. Y. (2009): Peroxisome proliferator-activated receptor activation by a short-term feeding of zingerone in aged rats. J. Med. Food 12, 345-350 http://dx.doi.org/10.1089/jmf.2007.0660

Eslamparast T., Eghtesad S., Poustchi H., Hekmatdoost A. (2015): Recent advances in dietary supplementation, in treating nonalcoholic fatty liver disease. World J. Hepatol. 7, 204-212 http://dx.doi.org/10.4254/wjh.v7.i2.204

Fan J. G. (2007): An introduction of strategies for the management of nonalcoholic fatty liver disease (NAFLD) recommended by Asia Pacific Working Party on NAFLD. Zhonghua Gan Zang Bing Za Zhi 15, 552-553 (in Chinese)

Folch J., Lees M., Sloane Stanley G. H. (1957): A simple method for the isolation and purification of total lipides from animal tissues. J. Biol. Chem. 226, 497-509

Gastaldelli A., Cusi K., Pettiti M., Hardies J., Miyazaki Y., Berria R., Buzzigoli E., Sironi A. M., Cersosimo E., Ferrannini E., Defronzo R. A. (2007): Relationship between hepatic/visceral fat and hepatic insulin resistance in nondiabetic and type 2 diabetic subjects. Gastroenterology 133, 496-506 http://dx.doi.org/10.1053/j.gastro.2007.04.068

Ghayur M. N., Gilani A. H. (2005): Pharmacological basis for the medicinal use of ginger in gastrointestinal disorders. Dig. Dis. Sci. 50, 1889-1897 
http://dx.doi.org/10.1007/s10620-005-2957-2

Han L. K., Morimoto C., Zheng Y. N., Li W., Asami E., Okuda H., Saito M. (2008): Effects of zingerone on fat storage in ovariectomized rats. Yakugaku Zasshi 128, 1195-1201 (in Japanese) http://dx.doi.org/10.1248/yakushi.128.1195

Hemalatha K. L., Prince P. S. (2015): Preventive effects of zingerone on altered lipid peroxides and nonenzymatic antioxidants in the circulation of isoproterenol-induced myocardial infarcted rats. J. Biochem. Mol. Toxicol. 29, 63-69 http://dx.doi.org/10.1002/jbt.21668

Hemalatha K. L., Stanely Mainzen Prince P. (2015): Antihyperlipidaemic, antihypertrophic, and reducing effects of zingerone on experimentally induced myocardial infarcted rats. J. Biochem. Mol. Toxicol. 29, 182-188 http://dx.doi.org/10.1002/jbt.21683

Huang X., Eriksson K. F., Vaag A., Lehtovirta M., Hansson M., Laurila E., Kanninen T., Olesen B. T., Kurucz I., Koranyi L., Groop L. (1999): Insulin-regulated mitochondrial gene expression is associated with glucose flux in human skeletal muscle. Diabetes 48, 1508-1514 http://dx.doi.org/10.2337/diabetes.48.8.1508

Kabuto H., Nishizawa M., Tada M., Higashio C., Shishibori T., Kohno M. (2005): Zingerone [4-(4-hydroxy-3-methoxyphenyl)2-butanone] prevents 6-hydroxydopamine-induced dopamine depression in mouse striatum and increases superoxide scavenging activity in serum. Neurochem. Res. 30, 325-332 http://dx.doi.org/10.1007/s11064-005-2606-3

Kawasaki T., Igarashi K., Koeda T., Sugimoto K., Nakagawa K., Hayashi S., Yamaji R., Inui H., Fukusato T., Yamanouchi T. (2009): Rats fed fructose-enriched diets have characteristics of nonalcoholic hepatic steatosis. J. Nutr. 139, 2067-2071 http://dx.doi.org/10.3945/jn.109.105858

Kumar L., Chhibber S., Harjai K. (2013): Zingerone inhibit biofilm formation and improve antibiofilm efficacy of ciprofloxacin against Pseudomonas aeruginosa PAO1. Fitoterapia 90, $73-78$ http://dx.doi.org/10.1016/j.fitote.2013.06.017

Kumar L., Chhibber S., Harjai K. (2014): Zingerone suppresses liver inflammation induced by antibiotic mediated endotoxemia through down regulating hepatic mRNA expression of inflammatory markers in Pseudomonas aeruginosa peritonitis mouse model. PLoS One 9, e106536 http://dx.doi.org/10.1371/journal.pone.0106536

Lewis J. R., Mohanty S. R. (2010): Nonalcoholic fatty liver disease: a review and update. Dig. Dis. Sci. 55, 560-578 http://dx.doi.org/10.1007/s10620-009-1081-0

Lieber C. S., Leo M. A., Mak K. M., Xu Y., Cao Q., Ren C., Ponomarenko A., DeCarli L. M., (2004): Model of nonalcoholic steatohepatitis. Am. J. Clin. Nutr. 79, 502-509

Lim J. S., Mietus-Snyder M., Valente A., Schwarz J. M., Lustig R. H. (2010): The role of fructose in the pathogenesis of NAFLD and the metabolic syndrome. Nat. Rev. Gastroenterol. Hepatol. $7,251-264$ http://dx.doi.org/10.1038/nrgastro.2010.41

Loria P., Lonardo A., Carulli L., Verrone A. M., Ricchi M., Lombardini S., Rudilosso A., Ballestri S., Carulli N. (2005): Review article: the metabolic syndrome and non-alcoholic fatty liver disease. Aliment. Pharmacol. Ther. 22, 31-36 http://dx.doi.org/10.1111/j.1365-2036.2005.02592.x

Magosso E., Ansari M. A., Gopalan Y., Abu Bakar M. R., Karim Khan N. A., Wong J. W., Ng B. H., Yuen K. H., Lutfi Shuaib I., Nesaretnam K. (2010): Prevalence of non-alcoholic fatty liver in a hypercholesterolemic population of northwestern peninsular Malaysia. Southeast Asian J. Trop. Med. Public Health 41, 936-942

Malaguarnera M., Di Rosa M., Nicoletti F., Malaguarnera L. (2009): Molecular mechanisms involved in NAFLD progression. J. Mol. Med. 87, 679-695 http://dx.doi.org/10.1007/s00109-009-0464-1

Manjunatha J. R., Bettadaiah B. K., Negi P. S., Srinivas, P. (2013): Synthesis of quinoline derivatives of tetrahydrocurcumin and zingerone and evaluation of their antioxidant and antibacterial attributes. Food Chem. 136, 650-658

http://dx.doi.org/10.1016/j.foodchem.2012.08.052

Mohan V., Farooq S., Deepa M., Ravikumar R., Pitchumoni C. S. (2009): Prevalence of non-alcoholic fatty liver disease in urban south Indians in relation to different grades of glucose intolerance and metabolic syndrome. Diabetes Res. Clin. Pract. 84, 84-91

http://dx.doi.org/10.1016/j.diabres.2008.11.039

Rafiq N., Younossi Z. M. (2009): Nonalcoholic fatty liver disease: a practical approach to evaluation and management. Clin. Liver Dis. 13, 249-266

http://dx.doi.org/10.1016/j.cld.2009.02.009

Rajakumar D. V., Rao M. N. (1994): Dehydrozingerone and its analogues as inhibitors of nonenzymatic lipid peroxidation. Pharmazie 49, 516-519

Rajan I., Narayanan N., Rabindran R., Jayasree P. R., Manish Kumar P. R. (2013): Zingerone protects against stannous chlorideinduced and hydrogen peroxide-induced oxidative DNA damage in vitro. Biol. Trace Elem. Res. 155, 455-459 http://dx.doi.org/10.1007/s12011-013-9801-x

Rao B. N., Rao B. S., Aithal B. K., Kumar M. R. (2009): Radiomodifying and anticlastogenic effect of Zingerone on Swiss albino mice exposed to whole body gamma radiation. Mutat. Res. 677, 33-41 http://dx.doi.org/10.1016/j.mrgentox.2009.05.004

Sanyal A. J., Campbell-Sargent C., Mirshahi F., Rizzo W. B., Contos M. J., Sterling R. K., Luketic V. A., Shiffman M. L., Clore J. N. (2001): Nonalcoholic steatohepatitis: association of insulin resistance and mitochondrial abnormalities. Gastroenterology 120, 1183-1192 http://dx.doi.org/10.1053/gast.2001.23256

Singh G., Kapoor I. P., Singh P., de Heluani C. S., de Lampasona M. P., Catalan C. A. (2008): Chemistry, antioxidant and antimicrobial investigations on essential oil and oleoresins of Zingiber officinale. Food Chem. Toxicol. 46, 3295-3302

http://dx.doi.org/10.1016/j.fct.2008.07.017

Spruss A., Kanuri G., Stahl C., Bischoff S.C., Bergheim I. (2012): Metformin protects against the development of fructoseinduced steatosis in mice: role of the intestinal barrier function. Lab. Invest. 92, 1020-1032 http://dx.doi.org/10.1038/labinvest.2012.75

Te Sligte K., Bourass I., Sels J. P., Driessen A., Stockbrugger R. W., Koek G. H. (2004): Non-alcoholic steatohepatitis: review of a growing medical problem. Eur. J. Intern. Med. 15, 10-21 
http://dx.doi.org/10.1016/j.ejim.2003.12.008

Teff K. L., Elliott S. S., Tschöp M., Kieffer T. J., Rader D., Heiman M., Townsend R. R., Keim N. L., D’Alessio D., Havel P. J. (2004): Dietary fructose reduces circulating insulin and leptin, attenuates postprandial suppression of ghrelin, and increases triglycerides in women. J. Clin. Endocrinol. Metab. 89, 2963-2972

http://dx.doi.org/10.1210/jc.2003-031855

Tetri L. H., Basaranoglu M., Brunt E. M., Yerian L. M., Neuschwander-Tetri B. A. (2008): Severe NAFLD with hepatic necroinflammatory changes in mice fed trans fats and a highfructose corn syrup equivalent. Am. J. Physiol. Gastrointest. Liver Physiol. 295, G987- 995

http://dx.doi.org/10.1152/ajpgi.90272.2008

Vernon G., Baranova A., Younossi Z. M. (2011): Systematic review: the epidemiology and natural history of non-alcoholic fatty liver disease and non-alcoholic steatohepatitis in adults. Aliment. Pharmacol. Ther. 34, 274-285 http://dx.doi.org/10.1111/j.1365-2036.2011.04724.x

Vinothkumar R., Vinothkumar R., Sudha M., Nalini N. (2014): Chemopreventive effect of zingerone against colon carcinogenesis induced by 1,2-dimethylhydrazine in rats. Eur. J. Cancer Prev. 23, 361-371 http://dx.doi.org/10.1097/CEJ.0b013e32836473ac

Vriens J., Nilius B., Vennekens R. (2008): Herbal compounds and toxins modulating TRP channels. Curr. Neuropharmacol. 6, 79-96

http://dx.doi.org/10.2174/157015908783769644

Yu A. S., Keeffe E. B. (2003): Elevated AST or ALT to nonalcoholic fatty liver disease: accurate predictor of disease prevalence? Am. J. Gastroenterol. 98, 955-956

http://dx.doi.org/10.1111/j.1572-0241.2003.07485.x

Received: May 6, 2015

Final version accepted: September 25, 2015

First published online: February 26, 2016 